\title{
Intermittent and daily smokers: two different socioeconomic patterns, and diverging influence of social participation
}

\author{
Martin Lindström, Per-Olof Östergren
}

\begin{abstract}
Objective-To investigate socioeconomic differences in intermittent and daily smoking, and to assess the association between social participation and these two smoking behaviours.

Design/setting/participants/

measurements-A population of 11837 individuals interviewed in 1992-94, aged 45-64 years, was investigated in this cross sectional study. A multivariate logistic regression model was used to assess socioeconomic differences in daily and intermittent smoking, adjusting for age, country of origin, previous/current diseases, and marital status. Finally, social participation as a measure of social capital was introduced in the multivariate model.
\end{abstract}

Results-When unskilled manual workers were compared to high level non-manual employees, odds ratios of $2.3 \quad(95 \%$ confidence interval (CI) 1.7 to 3.0 ) for men and 1.9 (95\% CI 1.4 to 2.5$)$ for women were found in regard to daily smoking, but odd ratios of only 0.7 (95\% CI 0.4 to 1.2 ) for men and $1.3(95 \%$ CI 0.7 to 2.4$)$ for women were found in regard to intermittent smoking. A decrease in the daily smoking odds ratios was found when social participation was introduced in the model, while the odds ratios regarding intermittent smoking were unaffected. Conclusions-There were no socioeconomic differences in intermittent smoking and no association with social participation, a result that contrasts sharply with the patterns of daily smoking. These findings have important implications for the discussion concerning social capital and preventive measures.

(Tobacco Control 2001;10:258-266)

Keywords: intermittent smoking; daily smoking; socioeconomic status; social participation; social capital

Department of Community Medicine, Malmö University Hospital, Lund University, S 20502

Malmö, Sweden

Correspondence to: Dr Lindström martin.lindstrom@ smi.mas.lu.se

Received 9 August 2000 and in revised form

20 March 2001. Accepted 24 April 2001 may be different causal mechanisms behind these two phenomena. The sociodemographic pattern for intermittent smokers contrasts sharply with the general sociodemographic smoking pattern in Europe and the USA. In the 1950s there were no socioeconomic differences in smoking, and women smoked to a much lesser extent than men. ${ }^{5}$ In the 1980 s and 1990s, the decrease in smoking prevalence has also involved a change in this pattern in most western countries. Smoking is now associated with low socioeconomic status, and in many countries women are smokers to the same extent as men. ${ }^{6-9}$

There is a strong biological mechanism that explains nicotine dependence. ${ }^{10-13}$ However, no biological model can account for the presence of socioeconomic differences in smoking. Psychological factors at the individual level have been shown to predict the inclination to initiate smoking cessation. ${ }^{14}{ }^{15}$ These individual characteristics are most likely affected by factors in the psychosocial environment. One study has suggested that psychosocial factors may protect very light smokers against nicotine dependence and higher tobacco consumption. ${ }^{16}$ Participation in social and civic life is a central factor to the understanding of empowerment. Israel and colleagues have defined empowerment, in its most general sense, as the ability of people to gain understanding and control over personal, social, economic, and political forces in order to take action to improve their own life situations. ${ }^{17}$ In contrast to reactive approaches that derive from a treatment or illness mode, the concept of empowerment is positive and proactive. Civic and social participation enables individuals and groups of individuals to assume responsibility and control concerning their own lives. ${ }^{18}$ Social participation has been shown in several studies to be associated with smoking. ${ }^{19} 20$ Social participation is one aspect of Putnam's social capital concept. Social capital concerns both the real and perceived possibilities for the citizens to participate, feel trust, have equal opportunities, and cooperate in society. ${ }^{21-23}$ Low levels of social capital indicate low perceived and real possibilities to influence one's own life situation-for example, the smoking status and the general health status of the individual. Social capital has in the literature been defined and operationalised as social participation and social trust. ${ }^{24}$ The aspect of social capital investigated in this study is social participation. However, no 
Table 1 Prevalence (\%) of smoking, socioeconomic, demographic, and social participation variables. The Malmö diet and cancer study 1992-94

\begin{tabular}{|c|c|c|c|c|c|c|}
\hline & \multicolumn{2}{|l|}{ Men } & \multicolumn{2}{|c|}{ Women } & \multicolumn{2}{|l|}{ Total } \\
\hline & $n$ & $\%$ & $n$ & $\%$ & $n$ & $\%$ \\
\hline \multicolumn{7}{|l|}{ Smoking status } \\
\hline Regular/daily smoker & 1346 & 25.0 & 1647 & 25.5 & 2993 & 25.3 \\
\hline Intermittent & 299 & 5.6 & 296 & 4.6 & 595 & 5.0 \\
\hline Stopped smoking & 2197 & 40.8 & 1746 & 27.1 & 3943 & 33.3 \\
\hline Never smoked & 1538 & 28.6 & 2765 & 42.8 & 4303 & 36.4 \\
\hline (Missing) & $(0)$ & & (3) & & (3) & \\
\hline \multicolumn{7}{|l|}{ Socioeconomic status } \\
\hline High level non-manual & 528 & 9.8 & 358 & 5.6 & 886 & 7.5 \\
\hline Middle level non-manual & 833 & 15.5 & 932 & 14.5 & 1765 & 14.9 \\
\hline Low level non-manual & 598 & 11.1 & 1587 & 24.6 & 2185 & 18.5 \\
\hline Skilled manual & 646 & 12.0 & 312 & 4.8 & 958 & 8.1 \\
\hline Unskilled manual & 604 & 11.2 & 1258 & 19.5 & 1862 & 15.8 \\
\hline Self employed & 794 & 14.8 & 349 & 5.4 & 1143 & 9.7 \\
\hline Pensioners & 953 & 17.7 & 1269 & 19.7 & 2222 & 18.8 \\
\hline Unemployed & 418 & 7.8 & 383 & 5.9 & 801 & 6.8 \\
\hline (Missing) & (6) & & (9) & & (15) & \\
\hline \multicolumn{7}{|l|}{ Age } \\
\hline $45-49$ years & 808 & 15.0 & 976 & 15.1 & 1784 & 15.1 \\
\hline $50-54$ years & 1574 & 29.3 & 1928 & 29.9 & 3502 & 29.6 \\
\hline $55-59$ years & 1468 & 27.3 & 1699 & 26.3 & 3167 & 26.8 \\
\hline $60-64$ years & 1530 & 28.4 & 1854 & 28.7 & 3384 & 28.6 \\
\hline (Missing) & $(0)$ & & (0) & & (0) & \\
\hline \multicolumn{7}{|l|}{ Country of origin } \\
\hline Sweden & 4653 & 86.5 & 5667 & 87.8 & 10320 & 87.2 \\
\hline $\begin{array}{l}\text { Other country } \\
\text { (Missing) }\end{array}$ & $\begin{array}{l}725 \\
(2)\end{array}$ & 13.5 & $\begin{array}{l}787 \\
(3)\end{array}$ & 12.2 & $\begin{array}{l}1512 \\
(5)\end{array}$ & 12.8 \\
\hline \multicolumn{7}{|l|}{ Self reported diseases* } \\
\hline No & 4466 & 83.2 & 5311 & 82.6 & 9777 & 82.9 \\
\hline Yes & 901 & 16.8 & 1118 & 17.4 & 2019 & 17.1 \\
\hline (Missing) & (13) & & $(28)$ & & $(41)$ & \\
\hline \multicolumn{7}{|l|}{ Marital status } \\
\hline Married & 3860 & 71.8 & 4039 & 62.6 & 7899 & 66.8 \\
\hline Unmarried & 603 & 11.2 & 569 & 8.8 & 1172 & 9.9 \\
\hline Divorced & 803 & 14.9 & 1354 & 21.0 & 2157 & 18.2 \\
\hline Widow/widower & 112 & 2.1 & 491 & 7.6 & 603 & 5.1 \\
\hline (Missing) & $(2)$ & & (4) & & (6) & \\
\hline \multicolumn{7}{|l|}{ Social participation } \\
\hline High & 3851 & 71.6 & 4635 & 71.8 & 8486 & 71.7 \\
\hline Low & 1529 & 28.4 & 1822 & 28.2 & 3351 & 28.3 \\
\hline (Missing) & $(0)$ & & $(0)$ & & (0) & \\
\hline Total & 5380 & & 6457 & & 11837 & \\
\hline
\end{tabular}

*Self reported previous or current diseases included myocardial infarction, stroke, intermittent claudication, diabetes mellitus, cancer, and asthma/chronic obstructive lung disease.

investigation on social participation or social capital, including intermittent smoking or the differentiation of social determinants between daily and intermittent smoking, has previously been conducted to our knowledge.

Our paper aims to characterise and compare daily and intermittent (non-daily) smokers to non-smokers according to sociodemographic characteristics. The aim is also to investigate whether socioeconomic differences in smoking can be observed for both daily and intermittent smokers, and whether the socioeconomic patterns observed for daily and intermittent smokers are associated with social participation as a measure of social capital.

\section{Material and methods}

STUDY POPULATION

The Malmö diet and cancer study (MDCS) is a prospective cohort study in Malmö, the third largest city of Sweden with approximately 250000 inhabitants. Recruitment to the MDCS started in the spring of 1991 and the final participants were examined in the autumn of 1996. The MDCS source population consists of all men and women living in Malmö born between 1926 and $1945(n=53$ 000), and was extended to some older and younger age groups in 1995-96. The total participation rate in the MDCS was $40.6 \%$.

The social participation variable was not included in the first version of the questionnaire used in 1991-92, and a third version of the questionnaire was used in 1994-96. The present study population consists of every person who participated in the MDCS during the two year period from March 1992 until August 1994, and were aged 45-64 years $(n=11837)$. This represents a quarter of the entire population aged 45-64 years in Malmö.

Subjects were recruited at random by postal invitation. Some respondents $(25.2 \%)$ came to the examination spontaneously. ${ }^{25}$ The baseline questionnaire was completed at home and checked for missing answers by the diet assistants at the second visit to the MDCS project office a few weeks later.

\section{DEFINITIONS}

There were four possible alternative answers to the question "Do you smoke?": "Yes, I smoke daily" (daily smoker); "Yes, I smoke sometimes (not daily)" (intermittent smoker); "No, I have stopped smoking"; and "No, I have never smoked". Non-smoker status was defined as having stopped smoking or having never smoked (alternatives 3 and 4).

Classification of socioeconomic status (SES) was based on data about job title, working tasks, and position obtained in the questionnaire. The procedure was identical to the one used in the Swedish population census. ${ }^{26}$ The employee groups include skilled and unskilled manual workers, non-manual employees in low and medium position, and high level non-manual employees in leading positions or with university degree.

The self employed group is very heterogeneous, comprising physicians, dentists, and large company employers on the one hand, and small shopkeepers, self employed carpenters, etc, on the other.

The unemployed were analysed as a separate group of individuals, composed of persons who are outside the active workforce but still available as a potential part of the workforce, thus excluding self retired individuals.

Pensioners were analysed as a separate category completely outside the workforce. The group of pensioners younger than 65 years consists largely of those people who have received disability pensions.

In regard to country of origin, all persons born in countries other than Sweden were merged into a single category. Thus, the two categories used in the analysis are "Sweden" or "other".

Self reported diseases might modify the inclination to stop smoking. Self reported previous or current diseases included myocardial infarction, stroke, intermittent claudication, diabetes mellitus, cancer or asthma/chronic obstructive lung disease.

Marital status included four categories: married, unmarried, divorced, and widow/ widower. 
Table 2 Crude odds ratios (OR) and 95\% confidence intervals (CI) of daily and intermittent smoking in relation to demographic, socioeconomic and psychosocial variables: men. Malmö diet and cancer study 1992-94

\begin{tabular}{|c|c|c|c|c|c|}
\hline & \multirow[b]{2}{*}{$n$} & \multicolumn{2}{|c|}{ Daily smokers } & \multicolumn{2}{|c|}{ Intermittent smokers } \\
\hline & & $\%$ & OR $(95 \% C I)$ & $\%$ & OR $(95 \% C I)$ \\
\hline \multicolumn{6}{|l|}{ Socioeconomic status } \\
\hline High level non-manual & 528 & 18.4 & 1.0 & 6.4 & 1.0 \\
\hline Middle level non-manual & 833 & 18.8 & $1.0(0.8$ to 1.4$)$ & 4.4 & $0.7(0.4$ to 1.1$)$ \\
\hline Low level non-manual & 598 & 20.1 & $1.1(0.8$ to 1.5$)$ & 6.9 & $1.1(0.7$ to 1.7$)$ \\
\hline Skilled manual & 646 & 24.9 & 1.5 (1.1 to 2.0$)$ & 5.6 & $0.9(0.5$ to 1.4$)$ \\
\hline $\begin{array}{l}\text { Unskilled manual } \\
\text { (Missing) }\end{array}$ & $\begin{array}{c}604 \\
(2171)\end{array}$ & 33.8 & $2.3(1.7$ to 3.0$)$ & 4.8 & $0.7(0.4$ to 1.2$)$ \\
\hline \multicolumn{6}{|l|}{ Vocationally active } \\
\hline Employees & 3209 & 23.0 & 1.0 & 5.5 & 1.0 \\
\hline $\begin{array}{l}\text { Self employed } \\
\text { (Missing) }\end{array}$ & $\begin{array}{c}794 \\
(1377)\end{array}$ & 22.8 & $1.0(0.8$ to 1.2$)$ & 7.1 & $1.3(0.95$ to 1.8$)$ \\
\hline \multicolumn{6}{|c|}{ Vocationally active and unemployed $\dagger$} \\
\hline All employed & 4003 & 23.0 & 1.0 & 5.8 & 1.0 \\
\hline $\begin{array}{l}\text { Unemployed } \\
\text { (Missing) }\end{array}$ & $\begin{array}{c}418 \\
(959)\end{array}$ & 34.4 & $1.8(1.4$ to 2.2$)$ & 5.0 & $0.9(0.5$ to 1.4$)$ \\
\hline \multicolumn{6}{|l|}{ Workforce v pensioners $\ddagger$} \\
\hline Workforce & 4421 & 24.1 & 1.0 & 5.7 & 1.0 \\
\hline Pensioners & 953 & 29.4 & $1.3(1.1$ to 1.5$)$ & 4.7 & $0.8(0.6$ to 1.1$)$ \\
\hline (Missing) & (6) & & & & \\
\hline \multicolumn{6}{|l|}{ Age } \\
\hline $45-49$ years & 808 & 27.5 & 1.0 & 6.8 & 1.0 \\
\hline $50-54$ years & 1574 & 25.9 & $0.9(0.8$ to 1.1$)$ & 6.2 & $0.9(0.6$ to 1.3$)$ \\
\hline $55-59$ years & 1468 & 26.1 & $0.9(0.8$ to 1.1$)$ & 5.1 & $0.7(0.5$ to 1.1$)$ \\
\hline $60-64$ years & 1530 & 21.8 & $0.7(0.6$ to 0.9$)$ & 4.7 & 0.7 (0.5 to 0.97$)$ \\
\hline (Missing) & $(0)$ & & & & \\
\hline \multicolumn{6}{|l|}{ Country of origin } \\
\hline Sweden & 4653 & 24.7 & 1.0 & 5.3 & 1.0 \\
\hline Other country & 725 & 27.0 & $1.1(0.9$ to 1.3$)$ & 7.0 & $1.3(0.98$ to 1.8$)$ \\
\hline (Missing) & (2) & & & & \\
\hline \multicolumn{6}{|l|}{ Self reported diseases $\rrbracket$} \\
\hline No & 4466 & 25.5 & 1.0 & 5.5 & 1.0 \\
\hline Yes & 901 & 22.8 & $0.9(0.7$ to 1.02$)$ & 6.0 & $1.1(0.8$ to 1.4$)$ \\
\hline (Missing) & (13) & & & & \\
\hline \multicolumn{6}{|l|}{ Marital status } \\
\hline Married & 3860 & 21,9 & 1.0 & 5.5 & 1.0 \\
\hline Unmarried & 603 & 31,3 & $1.6(1.3$ to 2.0$)$ & 6.1 & $1.1(0.8$ to 1.6$)$ \\
\hline Divorced & 803 & 34,9 & 1.9 (1.6 to 2.2$)$ & 5.9 & $1.1(0.8$ to 1.5$)$ \\
\hline Widow/widower & 112 & 26,8 & $1.3(0.9$ to 2.0$)$ & 3.6 & $0.6(0.2$ to 1.8$)$ \\
\hline (Missing) & (2) & & & & \\
\hline \multicolumn{6}{|l|}{ Social participation } \\
\hline High & 3851 & 21.1 & 1.0 & 5.8 & 1.0 \\
\hline $\begin{array}{l}\text { Low } \\
\text { (Missing) }\end{array}$ & $\begin{array}{l}1529 \\
(6)\end{array}$ & 34.9 & $2.0(1.8$ to 2.3$)$ & 4.9 & $0.8(0.6$ to 1.1$)$ \\
\hline Total & 5380 & & & & \\
\hline
\end{tabular}

^Employees (five groups) versus self employed.

†All employed (six groups including self employed) versus unemployed.

¥Workforce (five employee groups, self employed and unemployed) versus pensioners.

$\S$ Self reported previous or current diseases included myocardial infarction, stroke, intermittent claudication, diabetes mellitus, cancer, and asthma/chronic obstructive lung disease.

Social participation (during the past year) describes how actively the person takes part in the activities of formal and informal groups in society. Respondents were asked whether in the previous 12 months they had been involved in any of the following 13 activities: study circle/course at workplace, other study circle/course, union meeting, meeting of other organisations, theatre/cinema, arts exhibition, church, sports event, writing a letter to the editor of a newspaper/journal, demonstration, night club/entertainment, large gathering of relatives, and private party. It was measured as an index consisting of 13 items and dichotomised. If three alternatives or less were indicated, the social participation of that individual was classified as low.

The validity and reliability of the social participation index variable was tested in a previous study concerning the MDCS data material, and the $\kappa$ coefficient was 0.70 , indicating an acceptable reliability. Furthermore, the construct validity analysed by Cronbach's $\alpha$ was 0.61 for the social participation index variable. The analysis of construct validity indicated that the social participation index variable measured other aspects of the psychosocial environment than the social support variables. $^{27}$

\section{STATISTICS}

Crude odds ratios and 95\% confidence intervals $(95 \% \mathrm{CI})$ were calculated in order to analyse associations between different demographic and socioeconomic variables, social participation, and daily and intermittent smoking. The multivariate analysis was performed in order to investigate the potential importance of various confounders and to analyse the importance of social participation on the 
Table 3 Crude odds ratios (OR) and 95\% confidence intervals (CI) of daily and intermittent smoking in relation to demographic, socioeconomic and psychosocial variables: women. Malmö diet and cancer study 1992-94

\begin{tabular}{|c|c|c|c|c|c|}
\hline & & Daily & kers & Inter & ent smokers \\
\hline & $n$ & $\%$ & OR $(95 \% C I)$ & $\%$ & OR $(95 \% C I)$ \\
\hline Socioeconomic status & & & & & \\
\hline High level non-manual & 358 & 20.1 & 1.0 & 4.2 & 1.0 \\
\hline Middle level non-manual & 932 & 21.8 & $1.1(0.8$ to 1.5$)$ & 5.3 & $1.3(0.7$ to 2.3$)$ \\
\hline Low level non-manual & 1587 & 24.3 & $1.3(0.9$ to 1.7$)$ & 4.6 & $1.1(0.6$ to 1.9$)$ \\
\hline Skilled manual & 312 & 26.3 & $1.4(0.99$ to 2.0$)$ & 2.9 & $0.7(0.3$ to 1.6$)$ \\
\hline $\begin{array}{l}\text { Unskilled manual } \\
\text { (Missing) }\end{array}$ & $\begin{array}{l}1257 \\
(2011)\end{array}$ & 30.0 & $1.7(1.3$ to 2.3$)$ & 5.2 & $1.2(0.7$ to 2.2$)$ \\
\hline Vocationally active $^{\star}$ & & & & & \\
\hline Employees & 4446 & 25.3 & 1.0 & 4.7 & 1.0 \\
\hline $\begin{array}{l}\text { Self employed } \\
\text { (Missing) }\end{array}$ & $\begin{array}{c}349 \\
(1662)\end{array}$ & 22.1 & $0.8(0.6$ to 1.1$)$ & 6.3 & $1.4(0.9$ to 2.1$)$ \\
\hline Vocationally active and une & & & & & \\
\hline All employed & 4795 & 25.1 & 1.0 & 4.9 & 1.0 \\
\hline $\begin{array}{l}\text { Unemployed } \\
\text { (Missing) }\end{array}$ & $\begin{array}{c}383 \\
(1279)\end{array}$ & 27.7 & $1.2(0.9$ to 1.5$)$ & 3.7 & $0.7(0.4$ to 1.3$)$ \\
\hline Workforce v pensioners $\ddagger$ & & & & & \\
\hline Workforce & 5178 & 25.3 & 1.0 & 4.8 & 1.0 \\
\hline Pensioners & 1267 & 26.9 & $1.1(0.95$ to 1.3$)$ & 3.8 & $0.8(0.6$ to 1.1$)$ \\
\hline (Missing) & $(12)$ & & & & \\
\hline Age & & & & & \\
\hline $45-49$ years & 976 & 31.9 & 1.0 & 5.9 & 1.0 \\
\hline $50-54$ years & 1928 & 29.5 & $0.9(0.8$ to 1.1$)$ & 5.7 & $0.9(0.7$ to 1.3$)$ \\
\hline $55-59$ years & 1699 & 23.1 & $0.6(0.5$ to 0.8$)$ & 3.8 & $0.6(0.4$ to 0.9$)$ \\
\hline 60-64 years & 1851 & 20.3 & $0.5(0.46$ to 0.7$)$ & 3.5 & $0.6(0.4$ to 0.8$)$ \\
\hline (Missing) & (3) & & & & \\
\hline Country of origin & & & & & \\
\hline Sweden & 5666 & 25.4 & 1.0 & 4.7 & 1.0 \\
\hline Other country & 785 & 26.5 & $1.1(0.9$ to 1.3$)$ & 3.9 & $0.8(0.6$ to 1.2$)$ \\
\hline (Missing) & (6) & & & & \\
\hline Self reported diseases $₫$ & & & & & \\
\hline No & 5311 & 25.0 & 1.0 & 4.6 & 1.0 \\
\hline Yes & 1116 & 27.5 & $1.1(0.98$ to 1.3$)$ & 4.5 & $0.97(0.7$ to 1.3$)$ \\
\hline (Missing) & $(30)$ & & & & \\
\hline Marital status & & & & & \\
\hline Married & 4038 & 20.6 & 1.0 & 4.0 & 1.0 \\
\hline Unmarried & 569 & 28.6 & 1.5 (1.3 to 1.9$)$ & 4.2 & $1.0(0.7$ to 1.6$)$ \\
\hline Divorced & 490 & 36.7 & $2.2(1.9$ to 2.5$)$ & 6.2 & $1.6(1.2$ to 2.1$)$ \\
\hline Widow/widower & 6450 & 31.4 & $1.8(1.4$ to 2.2$)$ & 4.5 & $1.1(0.7$ to 1.8$)$ \\
\hline (Missing) & (7) & & & & \\
\hline Social participation & & & & & \\
\hline High & 4635 & 22.9 & 1.0 & 4.7 & 1.0 \\
\hline Low & 1819 & 32.1 & $1.6(1.4$ to 1.8$)$ & 4.4 & $1.1(0.8$ to 1.4$)$ \\
\hline (Missing) & (3) & & & & \\
\hline Total & 6457 & & & & \\
\hline
\end{tabular}

^Employees (five groups) versus self employed.

†All employed (six groups including self employed) versus unemployed.

¥Workforce (five employee groups, self employed and unemployed) versus pensioners

$\S$ Self reported previous or current diseases included myocardial infarction, stroke, intermittent claudication, diabetes mellitus, cancer, and asthma/chronic obstructive lung disease.

socioeconomic differences in daily and intermittent smoking, respectively. The daily and intermittent smokers were compared to non-smokers in all the multivariate analyses. The effects of the covariates were explored by logistic regression analysis concerning the association between social participation and the odds ratio of daily and intermittent smoking, respectively. The statistical analysis was performed using the SPSS software package. ${ }^{28}$

\section{Results}

Table 1 shows that the men in our study were more often self employed, non-manual employees in higher positions, and skilled manual workers, and the women were more often non-manual employees in lower and middle positions and unskilled manual workers. These differences further support our notion that men and women should be analysed separately. The proportion of persons born in countries other than Sweden were almost the same for men and women $(13.5 \%$ and $12.2 \%$, respectively).

The proportion of both daily and intermittent smokers was the same for both sexes. The proportion of persons who had never smoked was much larger among women $(42.8 \%)$ than among men $(28.6 \%)(\mathrm{p}<0.001$, $t$ test). On the other hand, the proportion of individuals that had stopped smoking was much larger among men $(40.8 \%)$ compared to women $(27.1 \%)$ ( $\mathrm{p}<0.001, t$ test). The sum proportion of non-smokers (according to our definition above) is thus approximately the same for men and women.

Tables 2 and 3 illustrate that there were significant socioeconomic differences in daily smoking among both men and women. For 
Table 4 Age adjusted and multivariate odds ratios (OR) and 95\% confidence intervals (CI) of daily and intermittent smoking compared to all non-smokers in socioeconomic groups: men. Malmö diet and cancer study 1992-94

\begin{tabular}{|c|c|c|c|c|c|c|}
\hline & \multicolumn{3}{|l|}{ Daily smoking } & \multicolumn{3}{|c|}{ Intermittent smoking } \\
\hline & $\begin{array}{l}\text { Adjusted }{ }^{\star} \mathrm{OR}, \\
95 \% \mathrm{CI}\end{array}$ & $\begin{array}{l}\text { Adjusted }+ \text { OR, } \\
95 \% \text { CI }\end{array}$ & $\begin{array}{l}\text { Adjusted } \neq \text { OR, } \\
95 \% \text { CI }\end{array}$ & $\begin{array}{l}\text { Adjusted }{ }^{*} \mathrm{OR}, \\
95 \% \mathrm{CI}\end{array}$ & $\begin{array}{l}\text { Adjusted }+ \text { OR, } \\
95 \% \text { CI }\end{array}$ & $\begin{array}{l}\text { Adjusted } \neq \text { OR, } \\
95 \% \text { CI }\end{array}$ \\
\hline \multicolumn{7}{|l|}{ Socioeconomic status } \\
\hline High level non-manual & 1.0 & 1.0 & 1.0 & 1.0 & 1.0 & 1.0 \\
\hline Middle level non-manual & $1.0(0.8$ to 1.3$)$ & $1.0(0.8$ to 1.4$)$ & $1.0(0.8$ to 1.3$)$ & $0.7(0.4$ to 1.1$)$ & $0.7(0.4$ to 1.1$)$ & $0.7(0.4$ to 1.1$)$ \\
\hline Low level non-manual & $1.1(0.8$ to 1.5$)$ & $1.1(0.9$ to 1.6$)$ & $1.1(0.8$ to 1.4$)$ & $1.1(0.7$ to 1.7$)$ & $1.1(0.7$ to 1.7$)$ & $1.1(0.7$ to 1.8$)$ \\
\hline Skilled manual & $1.5(1.1$ to 2.0$)$ & $1.5(1.1$ to 2.0$)$ & $1.3(1.00$ to 1.8$)$ & $0.9(0.5$ to 1.4$)$ & $0.8(0.5$ to 1.3$)$ & $0.8(0.5$ to 1.4$)$ \\
\hline Unskilled manual & $2.3(1.7$ to 3.0$)$ & $2.3(1.7$ to 3.0$)$ & $1.9(1.4$ to 2.5$)$ & $0.7(0.4$ to 1.2$)$ & $0.7(0.4$ to 1.2$)$ & $0.7(0.4$ to 1.2$)$ \\
\hline \multicolumn{7}{|l|}{ Vocationally active\} $\\
{\hline \text { Employees }} &{1.0} &{1.0} &{1.0} &{1.0} &{1.0} &{1.0} \\
{\hline \text { Self employed }} &{1.0(0.8 \text { to } 1.2)} &{1.0(0.8 \text { to } 1.2)} &{1.0(0.8 \text { to } 1.2)} &{1.3(0.95 \text { to } 1.8)} &{1.3(0.96 \text { to } 1.8)} &{1.3(0.95 \text { to } 1.8)} \\
{\hline \multicolumn{7}{|c|}{\text { Vocationally active and unemployed }}\text { Vocationally active and unemployed }} \\
{\hline \text { All employed }} &{1.0} &{1.0} &{1.0} &{\text { 1. } 0} &{1.0} &{1.0} \\
{\hline \text { Unemployed }} &{1.8(1.4 \text { to } 2.2)} &{1.8(1.4 \text { to } 2.2)} &{1.6(1.3 \text { to } 2.0)} &{0.9(0.5 \text { to } 1.4)} &{0.8(0.5 \text { to } 1.3)} &{0.8(0.5 \text { to } 1.4)} \\
{\hline \multicolumn{7}{|l|}{\text { Workforce v pensioners }{ }^{\star \star}}\text { Workforce v pensioners } { } ^ { \star \star }} \\
{\hline \text { Workforce }} &{1.0} &{1.0} &{1.0} &{1.0} &{1.0} &{1.0} \\
{\hline \text { Pensioners }} &{1.6(1.3 \text { to } 1.8)} &{1.6(1.3 \text { to } 1.8)} &{1.3(1.1 \text { to } 1.6)} &{0.9(0.7 \text { to } 1.3)} &{0.9(0.6 \text { to } 1.3)} &{0.9(0.6 \text { to } 1.3)} \\
$\hline}
\end{tabular}

*Adjustment for age.

tAdjustment made for age, ethnicity, self reported diseases, and marital status.

†Adjustment made for age, ethnicity, self reported disease, marital status, and social participation.

§Employees (five groups) versus self employed.

AAll employed (six groups including self employed) versus unemployed.

$\star \star$ Workforce (five employee groups, self employed and unemployed) versus pensioners.

both sexes, the SES groups skilled and unskilled manual workers showed significantly higher odds ratios for daily smoking, compared to the non-manual high level reference group. The unemployed men had significantly higher odds ratios for daily smoking compared to the whole employed group. The male pensioners also had higher odds ratios for daily smoking compared to the whole workforce. On the other hand, no significant socioeconomic differences in intermittent smoking were seen, either for men or for women. Unmarried and divorced men had significantly higher odds ratios for daily smoking than married men. The same patterns of higher odds ratios for daily smoking were seen for unmarried and divorced women, and widows. In contrast, the odds ratio for being an intermittent smoker was only significantly higher among women who were divorced. Men with low social participation had an odds ratio of 2.0 (95\% CI 1.8 to 2.3 ) for being a daily smoker, while the corresponding odds ratio for being an intermittent smoker was non-significant $(0.8$, $95 \%$ CI 0.6 to 1.1$)$. Among women, individuals with low social participation had an odds ratio of 1.6 (95\% CI 1.4 to 1.8 ) for daily smoking. In contrast, women with low social participation only had a non-significant odds ratio of 1.1 (95\% CI 0.8 to 1.4 ) for intermittent smoking.

Tables 4 and 5 show that the SES patterns among daily smokers and the lack of SES patterns among intermittent smokers compared to non-smokers did not change when age, country of origin, self reported diseases, and marital status were included in the multivariate logistic regression models, neither for men nor

Table 5 Age adjusted and multivariate odds ratios (OR) and 95\% confidence intervals (CI) of daily and intermittent smoking compared to all non-smokers in socioeconomic groups: women. Malmö diet and cancer study 1992-94

\begin{tabular}{|c|c|c|c|c|c|c|}
\hline & \multicolumn{3}{|l|}{ Daily smoking } & \multicolumn{3}{|c|}{ Intermittent smoking } \\
\hline & $\begin{array}{l}\text { Adjusted } \\
95 \% \mathrm{CI}\end{array}$ & $\begin{array}{l}\text { Adjusted }+ \text { OR, } \\
95 \% C I\end{array}$ & $\begin{array}{l}\text { Adjusted } \neq \text { OR, } \\
95 \% \text { CI }\end{array}$ & $\begin{array}{l}\text { Adjusted } \\
95 \% \mathrm{CI}\end{array}$ & $\begin{array}{l}\text { Adjusted }+ \text { OR, } \\
95 \% \text { CI }\end{array}$ & $\begin{array}{l}\text { Adjusted } \neq \text { OR, } \\
95 \% \text { CI }\end{array}$ \\
\hline \multicolumn{7}{|l|}{ Socioeconomic status } \\
\hline High level non-manual & 1.0 & 1.0 & 1.0 & 1.0 & 1.0 & 1.0 \\
\hline Middle level non-manual & $1.1(0.8$ to 1.5$)$ & $1.2(0.9$ to 1.6$)$ & $1.1(0.8$ to 1.6$)$ & $1.3(0.7$ to 2.3$)$ & $1.3(0.7$ to 2.4$)$ & $1.3(0.7$ to 2.4$)$ \\
\hline Low level non-manual & $1.3(1.01$ to 1.8$)$ & $1.4(1.01$ to 1.8$)$ & $1.3(0.96$ to 1.7$)$ & $1.1(0.6$ to 2.0$)$ & $1.1(0.6$ to 2.0$)$ & $1.1(0.6$ to 2.0$)$ \\
\hline Skilled manual & $1.5(1.02$ to 2.1$)$ & $1.5(1.02$ to 2.1$)$ & $1.4(0.9$ to 2.0$)$ & $0.7(0.3$ to 1.6$)$ & $0.7(0.3$ to 1.6$)$ & $0.7(0.3$ to 1.6$)$ \\
\hline Unskilled manual & $1.8(1.4$ to 2.4$)$ & $1.9(1.4$ to 2.5$)$ & $1.6(1.2$ to 2.2$)$ & $1.3(0.7$ to 2.3$)$ & $1.3(0.7$ to 2.4$)$ & $1.3(0.7$ to 2.4$)$ \\
\hline \multicolumn{7}{|l|}{ Vocationally active\ } \\
\hline Employees & 1.0 & 1.0 & 1.0 & 1.0 & 1.0 & 1.0 \\
\hline Self employed & $0.8(0.6$ to 1.1$)$ & $0.8(0.6$ to 1.1$)$ & $0.8(0.6$ to 1.1$)$ & $1.3(0.8$ to 2.1$)$ & $1.3(0.9$ to 2.1$)$ & $1.3(0.9$ to 2.1$)$ \\
\hline \multicolumn{7}{|c|}{ Vocationally active and unemployed } \\
\hline All employed & 1.0 & 1.0 & 1.0 & 1.0 & 1.0 & 1.0 \\
\hline Unemployed & $1.2(0.98$ to 1.6$)$ & $1.2(0.95$ to 1.5$)$ & $1.2(0.9$ to 1.5$)$ & $0.8(0.5$ to 1.4$)$ & $0.8(0.5$ to 1.4$)$ & $0.8(0.5$ to 1.4$)$ \\
\hline \multicolumn{7}{|l|}{ Workforce v pensioners $\star \star \star$} \\
\hline Workforce & 1.0 & 1.0 & 1.0 & 1.0 & 1.0 & 1.0 \\
\hline Pensioners & $1.5(1.3$ to 1.7$)$ & $1.4(1.2$ to 1.7$)$ & $1.3(1.1$ to 1.5$)$ & $1.0(0.7$ to 1.4$)$ & $1.0(0.7$ to 1.4$)$ & $1.0(0.7$ to 1.4$)$ \\
\hline
\end{tabular}

^Adjustment for age.

†Adjustment made for age, ethnicity, self reported diseases, and marital status.

¥Adjustment made for age, ethnicity, self reported disease, marital status, and social participation

§Employees (five groups) versus self employed.

TAll employed (six groups including self employed) versus unemployed.

$\star \star$ Workforce (five employee groups, self employed and unemployed) versus pensioners. 
Table 6 Logistic regression analysis of association between social participation and the odds ratio of daily and intermittent smoking, respectively, compared to all non-smokers and presented as crude odds ratio (OR), adjusted OR, and confidence intervals (95\% CI): men. The Malmö diet and cancer study 1992-94.

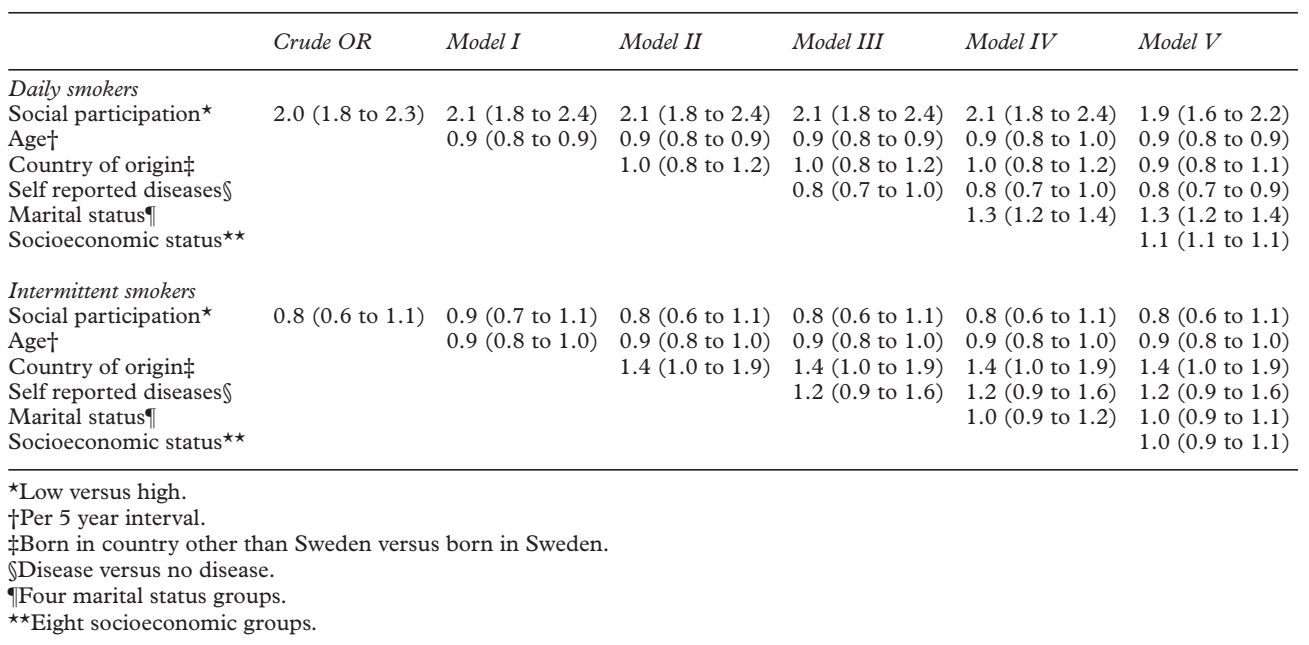

for women. Finally, when social participation was included in the models, the association between SES and daily smoking was considerably weakened because one third of the excess risk disappeared among the unskilled manual workers for both sexes. The odds ratios were reduced among men from 2.3 (95\% CI 1.7 to $3.0)$ to $1.9(95 \%$ CI 1.4 to 2.5$)$ for the unskilled manual workers. Social participation also reduced the female odds ratios from 1.9 (95\% CI 1.4 to 2.5 ) to 1.6 (95\% CI 1.2 to 2.2 ) for the unskilled manual workers. On the other hand, social participation had no association with intermittent smoking.

Since social participation was introduced in the final step in the regression analyses, it seemed important to analyse how much of the association between this variable and regular and intermittent smoking, respectively, that could be ascribed to the other variables in the model. Tables 6 and 7 show that age, country of origin, and self reported diseases had almost no effects on either the significant relation between social participation and daily smoking or the lack of significant association between social participation and intermittent smoking.
Marital status had some effect on the relation between social participation and daily smoking among both men and women.

Nicotine consumption in the form of oral snuff is a common habit in Sweden. ${ }^{29}$ The prevalence of snuff intake (yes/no) in the population of this study was $7.9 \%$ among men and $0.5 \%$ among women. When snuff consumption was included in the multivariate analysis (not shown in the tables), it had no effect on the odds ratios obtained.

When the respondents that came to the MDCS spontaneously were analysed separately, all the statistical patterns reported above remained unchanged (not shown in the tables).

\section{Discussion}

We found clear socioeconomic differences in daily smoking among both men and women. However, no significant socioeconomic differences in intermittent smoking were observed. After adjustment for potential confounders the inclusion of social participation in the final model of the multivariate analysis had a decreasing effect on the odds ratios and the socioeconomic differences in

Table 7 Logistic regression analysis of association between social participation and the odds ratio of daily and intermittent smoking, respectively, compared to all non-smokers and presented as crude odds ratio (OR), adjusted OR, and confidence intervals (95\% CI): women. The Malmö diet and cancer study 1992-94.

\begin{tabular}{|c|c|c|c|c|c|c|}
\hline & Crude OR & Model I & Model II & Model III & Model IV & Model V \\
\hline \multicolumn{7}{|l|}{ Daily smokers } \\
\hline Social participation ${ }^{\star}$ & $1.6(1.4$ to 1.8$)$ & $1.7(1.5$ to 2.0$)$ & $1.7(1.5$ to 2.0$)$ & $1.7(1.5$ to 1.9$)$ & $1.7(1.5$ to 1.9$)$ & $1.5(1.3$ to 1.8$)$ \\
\hline Aget & & $0.8(0.7$ to 0.8$)$ & $0.8(0.7$ to 0.8$)$ & $0.8(0.7$ to 0.8$)$ & $0.8(0.7$ to 0.8$)$ & $0.7(0.7$ to 0.8$)$ \\
\hline Country of origin $\ddagger$ & & & $1.0(0.8$ to 1.1$)$ & $1.0(0.8$ to 1.1$)$ & $0.9(0.8$ to 1.1$)$ & $0.9(0.7$ to 1.0$)$ \\
\hline Self reported diseases $₫$ & & & & $1.2(1.0$ to 1.4$)$ & $1.1(1.0$ to 1.3$)$ & $1.1(1.0$ to 1.3$)$ \\
\hline Marital status & & & & & $1.4(1.3$ to 1.4$)$ & $1.4(1.3$ to 1.4$)$ \\
\hline Socioeconomic status ${ }^{\star \star}$ & & & & & & $1.1(1.0$ to 1.1$)$ \\
\hline \multicolumn{7}{|l|}{ Intermittent smokers } \\
\hline Social participation ${ }^{\star}$ & $0.9(0.7$ to 1.2$)$ & $1.0(0.8$ to 1.3$)$ & $1.0(0.8$ to 1.3$)$ & $1.0(0.8$ to 1.3$)$ & $1.0(0.8$ to 1.3$)$ & $1.0(0.8$ to 1.3$)$ \\
\hline Age† & & $0.8(0.7$ to 0.9$)$ & $0.8(0.7$ to 0.9$)$ & $0.8(0.7$ to 0.9$)$ & $0.8(0.7$ to 0.9$)$ & $0.8(0.7$ to 0.9$)$ \\
\hline Country of origin $\ddagger$ & & & $0.8(0.6$ to 1.2$)$ & $0.8(0.6$ to 1.2$)$ & $0.8(0.6$ to 1.2$)$ & $0.8(0.6$ to 1.2$)$ \\
\hline Self reported diseases $\$$ & & & & $1.0(0.8$ to 1.4$)$ & $1.0(0.8$ to 1.4$)$ & $1.0(0.8$ to 1.4$)$ \\
\hline Marital status $\uparrow$ & & & & & $1.2(1.0$ to 1.3$)$ & $1.2(1.0$ to 1.3$)$ \\
\hline Socioeconomic status ${ }^{\star \star}$ & & & & & & $1.0(0.9$ to 1.1$)$ \\
\hline 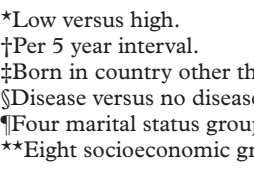 & Sweden versu & born in Sweden. & & & & \\
\hline
\end{tabular}


daily smoking. In contrast, social participation showed no association with intermittent smoking.

The present results could be influenced by selection bias, misclassification, and confounding.

A comparison with another investigation conducted in the city of Malmö during the same time period with a higher participation rate $(74 \%$ participation rate in the comparable age brackets) showed a good correspondence concerning SES, smoking, and social participation. On the other hand, people born abroad are under represented in the MDCS population. ${ }^{20}$ However, this is because approximately 2000 individuals of foreign origin were excluded from the whole study as a result of insufficient language skills (of all those interviewed from 1991 to 1996). Some studies have shown that non-participants differ from study participants in terms of smoking habits. ${ }^{3031}$ The smoking prevalence in these studies has been shown to be somewhat higher among non-participants. If individuals with low social participation also have a tendency of non-participation, this could lead to a situation where smokers with low social participation (that is, "exposed" cases) are over represented among non-participants. However, this would lead to an underestimation of the true association between smoking and social participation. Moreover, we do not find any plausible reason for assuming that the tendency of nonparticipation would be lower for intermittent smokers compared with daily smokers. Accordingly, the difference between these two groups in our study are probably not biased by selection to any important extent.

The validity of items assessing smoking has previously been analysed several times. The results have consistently shown that self reported tobacco smoking is a valid and reliable way to measure smoking habits in a population. ${ }^{32-37}$ Differential misclassification is not likely to have been present. Nondifferential misclassification seems to be a problem of less importance in this study, since non-differential misclassification tends to attenuate true differences, and the main results of this study show clear socioeconomic differences in daily smoking. The reliability and validity of the social participation variable showed a good or acceptable validity and reliability with no differences between the various SES groups found in a previous paper. ${ }^{27}$ The validity and reliability of the social participation variable was assessed using the cut-off ( $\leqslant 3$ items, $\geqslant 4$ items) to distinguish between low and high social participation, and this cut-off has also been used in Sweden since the 1960 s. $^{38}$

Age, sex, country of origin, self reported diseases, and marital status could be confounders of the associations between the psychosocial variables and smoking cessation. Adjusting for these variables, however, only marginally affected the estimates.

The $8 \%$ prevalence of snuff use among men may be regarded as low compared to the prevalence sometimes reported for Sweden.
However, other unpublished data from Scania in southern Sweden reveal the same prevalence of snuff use in this part of Sweden.

The cross sectional study design may be considered a weakness, because this design makes it impossible to follow the smoking history of the individuals. Some intermittent smokers may in fact be former daily smokers on their way to smoking cessation. However, this possibility does not contradict the main conclusions of this study. An objection against the aggregation of former and never smokers may also be raised. However, many former smokers stopped smoking many years ago, and the prevalence of low social participation was the same in these two groups.

Social participation has been shown in other studies to be associated with smoking and smoking cessation. ${ }^{19}{ }^{20}$ In this study, social participation was associated with daily smoking. Exposure to low social participation partly explained a part of the socioeconomic gradient in daily smoking. Social participation measures the individual's participation in several social activities within the life of modern society. Health related behaviours like smoking are a result of the interaction between a person and his or her environment. A person's relation to his or her environment can be viewed as a dynamic process, since environmental changes require continuous adaptation by the individual. The successful adaptation to changes in the environment requires both individual resources (for example, education and material resources) and social relations (for example, social support and social network). Daily smoking and its maintenance might function as a coping mechanism when the individual has low social participation. In contrast, intermittent smoking appears to be a different health behaviour phenomenon. Intermittent smoking was not associated with low socioeconomic status or low social participation.

The absence of socioeconomic differences in intermittent smoking is in accordance with previous findings that intermittent smokers have higher educational and occupational status than daily smokers. ${ }^{1}{ }^{4}$ Previous studies have also reported that intermittent smokers often are free of nicotine dependence. ${ }^{39}{ }^{40}$ This study has also shown their particular smoking behaviour to be unrelated to low social participation, while daily smoking and low social participation are significantly associated. This observation supports the notion that low social participation may act as a psychosocial barrier against smoking cessation among daily smokers. Furthermore, unpublished data from the public health survey in Malmö 1994, concerning a representative sample of men and women aged $20-80$ years and with a $71 \%$ participation rate, reveal that a much lower proportion of intermittent smokers $(32.3 \%)$ compared to daily smokers $(67.7 \%)$ have a desire to stop smoking; this also suggests that intermittent smoking is a different health related behaviour phenomenon, and not just a transitional stage between daily smoking and 
non-smoking. This "desire to stop smoking" item was not included in the MDCS questionnaire.

There are at least two possible explanations for the differences between intermittent and daily smokers in socioeconomic patterns and influence of social participation observed in this study. Firstly, as already mentioned, some smokers are biologically nicotine dependent and others are not. Nicotine dependence is a biological and not a socioeconomic or psychosocial characteristic. The nicotine dependent smokers are mostly daily smokers. The process of smoking cessation and its maintenance may be more difficult for nicotine dependent smokers in a less supportive environment - that is, an environment with a low level of social participation and social capital.

The second plausible explanation concerns the initiation of the smoking behaviour. Many smokers start being intermittent smokers during adolescence. ${ }^{41}$ A supportive environment with a high level of social participation prevents the progress from the state of intermittent smoking to the state of daily smoking. However, this explanation is impossible to confirm in this study, since the MDCS material does not contain any information concerning the levels of social participation at different stages in the life course of the participants. However, this notion seems to be supported by the fact that intermittent smokers do not differ from non-smokers in the level of social participation, while the odds ratio of low social participation is significantly higher among daily smokers compared to the non-smokers. The nicotine dependence could thus be an effect of the smoking habits that are determined by socioeconomic and psychosocial factors closely related to social participation and social capital.

These two tentative explanations are not mutually contradictory, but represent two possible hypotheses. However, because of the cross sectional design of this study, it is not possible to test any of these hypotheses. This would require a longitudinal study design.

The definition of social participation in this study is in accordance with Putnam's definition of social participation, which forms a part of his definition of social capital. ${ }^{21-23}$ The prevalences of the various sub-items of the social participation index variable differ somewhat. However, the socioeconomic gradients for the different items are very similar - that is, higher levels of different aspects of social participation are found in higher non-manual employees than in lower socioeconomic groups, with the exception of union meetings. Furthermore, the bivariate correlations between the items were in almost all the cases lower than 0.2 , with the exception of the bivariate correlation between theatre/cinema and arts exhibition $(r=0.39)$, study circle at workplace and union meeting $(r=0.25)$, and theatre/cinema and private party $(r=0.25)$. It thus seems that the social participation index variable measures different types of participatory activities in society. ${ }^{42}$ The findings of this study thus suggest an influence of social capital

\section{What this paper adds}

The scarce scientific literature on intermittent smokers indicates that intermittent smokers are younger and have higher educational and occupational status than daily (regular) smokers. These sociodemographic differences give reason to believe that there may be different causal mechanisms behind these two phenomena. The importance of social participation and social network has not been previously investigated in relation to intermittent smoking. The aim of this study was to investigate whether there were socioeconomic differences in intermittent and daily smoking, respectively, in a middle aged population, and to assess the association between social participation and these two smoking behaviours.

There were no socioeconomic differences in intermittent smoking and no association with social participation, a result that contrasts sharply with the clear socioeconomic differences and strong association with low social participation for daily smokers. These results indicate that there may be different causal mechanisms that explain intermittent smoking as opposed to daily smoking, and that the lack of sufficient levels of social participation and empowerment may be a barrier against smoking cessation among daily smokers but not among intermittent smokers.

in the link between socioeconomic status and daily smoking, but not intermittent smoking.

An important task is therefore to increase the understanding of which aspects of social capital are protective against daily smokingfor example, those generated by family and kinship compared with those from formal organisations such as unions, political parties, and study circles. ${ }^{43}$ Measures to improve social capital have been suggested as a means to improve health related behaviours that are not sufficiently influenced by individually targeted health promotion measures. ${ }^{44}$ The results of this study imply that preventive measures against daily tobacco smoking could be designed to improve at least certain aspects of social participation. A campaign, supported by the health services, to increase involvement (empowerment) in social and civic activities might have health promoting effects. ${ }^{18}$ The policy should thus affect the activities within formal and informal organisations and networks. This does not exclude an individual information strategy, particularly strategies directed at adolescents, but it further suggests yet another contextual dimension of preventive measures. The mechanisms that explain intermittent smoking remain to be disentangled.

This study was supported by grants from the Swedish Medical Research Council (B93-27X-10428-01A), the Swedish Council for Social Research (F0989/2000), the Swedish Research Council (D2000-0992:5, A14-5/618), the Medical Faculty, Council (D2000-0992:5, A14-5/618), the Medical Faculty,
Lund University, the National Institute of Public Health, and the Swedish Cancer Society (2684-D93-05XAA) 
1 Hennrikus DJ, Jeffrey RW, Lando HA. Occasional smoking in a Minnesota working population. Am $\mathcal{F}$ Public Health in a Minnesota

2 Evans NJ, Gilpin E, Pierce JP, et al. Occasional smoking among adults: evidence from the California tobacco survey. Tobacco Control 1992;1:169-75.

3 Anon. Cigarette smoking among adults-United States, 1992 , and changes in the definition of current cigarette smoking. MMWR Morb Mortal Wkly Rep 1994;43:342-6.

4 Husten CG, McCarty MC, Giovino GA, et al. Intermittent Smokers: a descriptive analysis of persons who have never smoked daily. Am f Public Health 1998;88:86-9.

5 Jarvis MJ. A profile of tobacco smoking. Addiction 1994;89:1371-6.

6 Smyth M, Browne J. General household survey 1990. London: HMSO, 1992.

7 Marmot MG, McDowall ME. Mortality decline and widening social inequalities. Lancet 1986;ii:274-6.

8 Graham H. Smoking prevalence among women in the European Community 1950-1990. Soc Sci Med 1996; 43:243-54.

9 Wersäll JP, Eklund G. The decline of smoking among Swedish men. Int F Epidemiol 1998;27:20-6.

10 Warburton DM, Revell AD, Thompson DH. Smokers of the future. Br $\mathcal{F}$ Addiction 1991;86:621-5.

11 Warburton DM. Smoking within reason. Fournal of Smoking-Related Disorders 1992;3:55-9.

12 Schachter S. Pharmacological and psychological determinants of smoking. In: Thornton RE, ed. Smoking behaviour, physiological and psychological influences. Edinburgh: Churchill-Livingstone, 1978.

13 Pomerleau OF, Pomerleau CS. Research on stress and smoking: progress and problems. Br F Addiction 1991; 86:599-604.

14 Gulliver SB, Hughes JR, Solomon LJ, et al. An investigation of self-efficacy, partner support and daily stresses as predictors of relapse to smoking in self-quitters. Addiction 1995;90:767-72.

15 Sanders D, Peveler R, Mant D, et al. Predictors of successful smoking cessation following advice from nurses in general smoking cessation following advice from
practise. Addiction 1993;88:1699-705.

16 Hajek P, West R, Wilson J. Regular smokers, lifetime very light smokers, and reduced smokers: comparison of psychosocial and smoking characteristics in women. Health Psychol 1995;14:195-20

17 Israel B, Checkoway B, Schulz A, et al. Health education and community empowerment: conceptualizing and measuring perceptions of individual, organizational and community control. Health Educ 1994;21:153.

18 Baum FE, Bush RA, Modra CC, et al. Epidemiology of participation: an Australian community study. 7 Epidemiol Community Health 2000;54:414-23.

19 Tillgren P, Haglund BJA, Lundberg M, et al. The sociodemographic pattern of tobacco cessation in the 1980s: results from a panel study of living condition surveys in Sweden. $\mathcal{f}$ Epidemiol Community Health 1996;50:625-30.

20 Lindström M, Hanson BS, Östergren P-O, Berglund G. of social participation. Scand F Public Health 2000;28:200 8.

21 Putnam RD. Making democracy work. Princeton, New Jersey: Princeton University Press, 1993.

22 Putnam RD. The prosperous community. Social capital and public life. The American Prospect 1993:35-42.

23 Putnam RD. Bowling alone: America's declining social capital. Fournal of Democracy 1995;6:65-78.

24 Kawachi I, Kennedy BP, Lochner K, et al. Social capital, income inequality, and mortality. Am F Public Health 1997; 87:1491-8.
25 Berglund G, Elmståhl S, Janzon L, et al. Design and feasibility. F Intern Med 1993;233:45-51.

26 Statistics Sweden. Occupations in population and housing census 1985 (FoB 1985) according to Nordic standard occupation classification and Swedish socio-economic classification. Stockholm: Statistics Sweden, 1985.

27 Hanson BS, Östergren P-O, Elmståhl S, et al. Reliability and validity assessments of measures of social network, social support and control-results from the Malmö shoulder and neck study. Scand f Soc Med 1997;25:249-57.

28 Norusis MJ. SPSS for Windows. Advanced Statistics. Release 6.0. Chicago: SPSS Inc, 1993

29 Schildt E-B, Eriksson M, Hardell L, et al. Oral Snuff, smoking habits and alcohol consumption in relation to oral cancer in a Swedish case-control study. Int $f$ Cancer 1998;77:341-6.

30 Boström C, Hallqvist J, Haglund BJA, et al. Socio-economic differences in smoking in an urban Swedish population. differences in smoking in an urb
Scand $\mathcal{F}$ Soc Med 1993;21:77-82.

31 Criqui $\mathrm{MH}$, Barret-Connor E, Austin M. Difference between respondents and non-respondents in a population-based cardiovascular disease study. $\mathrm{Am} \mathfrak{f}$ Epidemiol 1978;108:367-72.

32 Murray RP, Connett JE, Lauger GG, et al. Error in smoking measures: effects on relations of cotinine and carbon monoxide to self-reported smoking. Am $\mathcal{f}$ Public Health 1993;83:1251-6.

33 Tate JC, Pomerleau CS, Pomerleau OF. Pharmacological and non-pharmacological smoking motives: a replication and extension. Addiction 1994;89:321-30

34 Verkerk PH, Buitendijk SE, Verloove-Vanhorick SP. Differential misclassification of alcohol and cigarette consumption by pregnancy outcome. Int F Epidemiol 1994;23:1218-

35 Steffensen FH, Lauritzen T, Sörensen HT. Validity of self-reported smoking habits. Scand 7 Primary Health Care 1995;13:236-7.

36 US Department of Health and Human Services. The health benefits of smoking cessation. A report of the Surgeon General, 1990. Rockville, Maryland: Public Health Service, Centers for Disease Control, Office on Smoking and Health, 1990. (DHHS Publication No (CDC) 90-8416.)

37 Wells AJ, English PB, Posner SF, et al. Misclassification rates for current smokers misclassified as nonsmokers. Am 7 Public Health 1998;88,1503-9.

38 The National Central Bureau of Statistics. Living conditions. Isolation and togetherness - an outlook on social participation 1976. Report no. 18. Stockholm: The National Central Bureau of Statistics, 1980.

39 Owen N, Kent P, Wakefield M, et al. Lowrate smokers. Prev Med 1995;24:80-4.

40 Shiffman S. Tobacco "chippers"- individual differences in tobacco dependence. Psychopharmacology 1989;97:53947

41 Chassin L, Presson CC, Sherman SJ, et al. The natural history of cigarette smoking: predicting young-adult smoking outcomes from adolescent smoking patterns. Health Psychol 1990;9:701-16.

42 Lindström M. Social participation, social capital and socioeconomic differences in health-related behaviours [thesis]. Lund University, 2000.

43 Baum F. Social capital: is it good for your health? Issues for a public health agenda. $\mathcal{F}$ Epidemiol Community Health 1999;53:195-6

44 Lomas J. Social capital and health: implications for public health and epidemiology. Soc Sci Med 1998;47:1181-8. 